Neoklasik Paradigma Olarak Washington/Post Washington Uzlaşısının Yükselişi ve Düşüşü: Post-Keynesyen Alternatif Yaklaşım

\title{
The Rise and Fall of the Washington/Post Washington Consensus as a Neoclassical Paradigm and Alternative Recommendations of Post Keynesians Economics
}

\author{
Asst. Prof. Dr. Yelda Tekgül (Çukurova University, Turkey) \\ Prof. Dr. Mehmet Fatih Cin (Çukurova University, Turkey)
}

\begin{abstract}
The Washington Consensus was accepted as common wisdom on policies for development and growth. The set of policies of the Washington Consensus was applied to structural crisis in Latin America and developing economies. Williamson identified 10 policy instruments whose proper deployment Washington could muster a reasonable degree of consensus. Williamson summarizes the content of the Washington Consensus as macroeconomic prudence, outward orientation, domestic liberalization, and free market policies consistent with neoclassical mainstream economic theory. The policy set was modified to the point that Williamson substituted the original name with a new label "Post Washington Consensus. The "Post Washington Consensus" designated a "new set of policy reforms" for Latin America and Developing Countries. The aim of this paper is to compare the two sets of controversial policies, the "Washington Consensus" and "Post Washington Consensus" and offer an alternative based on the Post Keynesian framework. The goal of Post Keynesian framework is the promotion of sensible prudent economic and social development that is equitable, stable and sustainable. The main purpose of the Post Keynesian policy framework proposed in this paper is to go beyond the Post Washington Consensus by emphasizing the importance of a possible new direction for economic policy for developing countries.
\end{abstract}

\section{Giriș}

Sanayi devriminin yaşandığı 18. ve 19. Yüzyıllar, başta Amerika Birleşik Devletleri ve Avrupa ülkeleri olmak üzere tüm dünyada üretim-bölüşüm ilişkileri ile sosyal yaşam alanlarında bugünde içinde bulunduğumuz yeni bir sürecin ortaya çıkmasına yol açmıştır. Bu süreç Birinci ve İkinci Dünya Savaşlarıyla beraber 20.yüzyılda da sürerek 21. Yüzyıla kendisini taşımıştır. Bu sürecin iktisadi-sosyal ve siyasi anlamdaki genel adı kapitalizm olmuştur. İktisadi olarak piyasa mekanizmasının ve fiyat sinyallerinin üretim-tüketim ve bölüşüm ilişkilerinde tercih ve karar vermeyi belirlediği bu süreç (sistem), 1929 yılında başlayan ve 1939 yılında İkinci Dünya savaşının başladığı döneme kadar ağır bir krizden geçmiştir. Sistem savaş sonrasında Uluslararası Para Fonu (IMF) ve Dünya Bankası (WB) gibi teknik-politik kurumlar ile Birleşmiş Milletler gibi daha üst örgütlenmeler ile varlığını sürdürmüştür. Bu süreçte ulusal devletlerin kalkınma-büyüme ve korumacı eğilimleri ile sağlık ve eğitim altyapılarına verdikleri öncelikler temel karakteristik özellikler olmuştur. 1970'li y1llar iki petrol krizinin ortaya çıkardığı ekonomik durgunluk ve fiyat artışları gibi aynı sistem içerisinde yeni bir sürecin ortaya çıkmasına yol açmıştır.

Aynı zamanda 1970'lerin sonu ile 1990'ların başlarını kapsayan dönem piyasa mekanizması-fiyat sinyalleri gibi araçlara öncelik veren ve adına neoklasik/neoliberal denilen bir iktisadi ve siyasal anlayışın kalkınmabüyüme stratejisinde egemen olduğu yıllar olmuştur. Bu anlayış ulusal kalkınma stratejilerinde uygulanan ithal ikameci sanayileşme stratejilerinde de köklü bir değişikliği ortaya çıkarmıştır. Artık kişisel girişimler, piyasa liberalizmi, devletin küçültülmesi (belli alanlarda sınırlandırılması), büyüme stratejisinin ihracata dayandırılması ve dış dünyayla entegrasyonun ağırlık kazanması temel değerler dizisi olmuştur (Öniş ve Şenses, 2005).

ABD Hazine Bakanı N. Brady’nin Kasım 1989 yılında düzenlediği bir konferansta (komisyonun organizatörü John Williamson'dur) borç ödeme sorunları olan tüm üçüncü dünya ülkelerine yönelik olarak; yeni krediler, birikmiş borçlarda indirim sağlamak ve borç yükünü azaltmak için yapısal uyum programları çerçevesinde arz yönlü iktisat politikaları önerilmiştir. Bu gelişmeler sonucunda, 1989 yılında kalkınma iktisatçısı John Williamson tarafından "Washington Uzlaşısı" olarak adlandırılan neoklasik/neoliberal bir politika paketi gündeme gelmiştir. Bu paket başta Latin Amerika ülkelerine yönelik politika düzenlemeleri için kullanılmış daha sonra diğer yeni gelişen ekonomiler ve piyasa ekonomisine geçmeye çalışan eski sosyalist ülkelerde uygulamaya sokulmuştur. Washington Uzlaşısı aynı zamanda yeni politikalar içeren "Anti-Washington Uzlaşısı" sürecini de kendi içerisinde başlatmıştır (Marangos, 2008: 228).

Washington Uzlaşısı, merkezi Washington'da bulunan üç önemli kurumun -Dünya Bankası, Uluslararası Para Fonu, ABD Hazine Bakanlığ1- ülkelere tavsiye ettikleri ortak iktisat politikalarını ifade eder. Daha sonra bu uzlaşıya Dünya Ticaret Örgütü ve Avrupa Merkez Bankası da katılmıştır (Marangos, 2009: 350). Williamson, 
Washington Uzlaşısını makroekonomik tedbirler, dışa uyum, yurtiçi liberalizasyon ve serbest pazar politikaları olarak dört ana bölümde özetlemektedir. Bir anlamda Washington Uzlaşısı neoklasik/neoliberal ortodoks yaklaşımın en küçük ortak paydası olarak tanımlanmış olmaktadır.

\section{Orijinal Washington Uzlaşısı}

1990 yılındaki çalışmasında Williamson, Washington Uzlaşısında geniş bir ölçü olan ve tüm Latin Amerika ülkelerinde tercih edilen 10 politika önerisini şöyle açıklamaktadır (Williamson, 2004-2005: 196):
i. $\quad$ Bütçe açığı; enflasyon vergisine yol açmayacak kadar az olmalı
ii. Kamu harcamalarının daha hassas ve daha yüksek getiri sağlayacak alanlara kaydırılması (eğitim, sağlık, altyapı gibi).
iii. Vergi reformu; vergi tabanını genişletmek ve marjinal vergi oranını azaltmak
iv. Finansal liberalizasyon; faiz oranlarının piyasada belirlenmesi
v. Geleneksel olmayan ihracatta büyümeyi yeterince teşvik edecek rekabetçi reel kur politikası
vi. Ticaret liberalizasyonu; miktar kısıtlamalarının kademeli olarak \%10-20 tarifelerle değiştirilmesi
vii. Doğrudan yabancı yatırımların giriş engellerini ortadan kaldırmak
viii. $\quad$ Devlet işletmelerinin özelleştirilmesi
ix. Yeni firmaların girişini engelleyen veya rekabeti kısıtlayan düzenlemelerin kaldırılması (deregülasyon)
x. Özellikle kayıt dışı sektörler için mülkiyet haklarının güvence altına alınması

Washington Uzlaşısını oluşturan yukarıdaki on maddenin bir kısmı mali disiplin, kamu sektörü ve kamu bütçesi dengesinin sağlanması iken, bir kısmı da serbest piyasa anlayışının kurumsallaşmasını kapsayan (4.5.6.7. maddeler) maddelerdir. Son iki madde ise daha çok yabancı sermaye yatırımlarını ülkeye çekebilmek, mal ve sermaye akımlarının serbestleşmesini sağlayabilmek amacını gütmektedir. Ancak bu paketi uygulayan birçok ülkenin yeterli iktisadi büyümeye ulaşamadıkları gibi, finansal krizlerden dolayı daha da kırılgan bir duruma geldikleri gözlenmiştir (Rodrik, 2011:152).

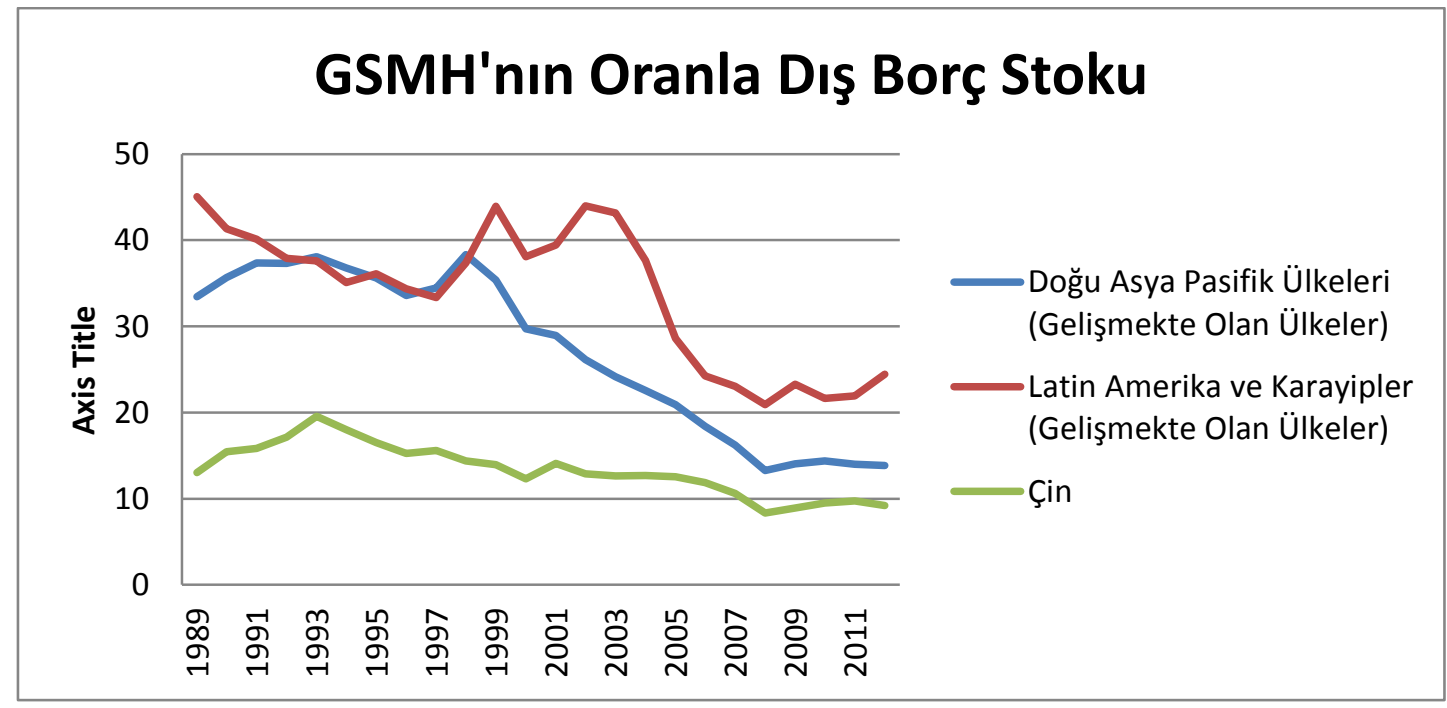

Şekil 1. Dış Borç Stokunun GSMG içindeki payı Kaynak: Dünya Bankası Veri Dağıtım sistemi

Latin Amerika, Doğu Asya, Rusya ve Türkiye'de sıkça ödemeler dengesi krizleri yaşanmış, özellikle yabancı sermaye giriş çıkışları bu krizlerin en belirgin nedeni olmuştur. Şekil 1, iki ülke grubu ve Çin'in dış borçlarındaki büyüklüğü göstermesi bakımından çarpıcı sonuçlar vermektedir. Washington Uzlaşısı dışında kalan Çin dışında bu sonuçlardan birincisi borçların yüksekliğidir. İkinci sonuç azalma eğilimi göstermesidir. Bu sonucun iki alt sonucundan söz edilebilir. Öncelikle büyüme oranı yükselmiş olabilir. Bu sonuç aynı ülke grupları için Şekil 2'de gösterilen büyüme oranlarına baktığımız zaman pek desteklenmemektedir. İkinci alt sonuç ise daha gerçekçi gözükmekte ve bu ülkelerden gelişmiş merkez ülkelere borç transferinin Washington Uzlaşısılyla artmış olmasidır.

Özellikle 1994-95 yılında Meksika'da yaşanan “Tekila Krizi” ile tablo daha da kötüleşmiş, bu kriz diğer coğrafyalara da taşınmıştır. Meksika'da yaşanan bu krizde dikkat çekici olan; düşük yurt içi tasarruf oranları nedeniyle yabancı fonlara aşırı bağımlı hale gelen bu ekonominin, yabancı sermaye piyasalarının hareketlerinden önemli oranda etkilenmesidir. Bu nedenle sağlam makroekonomik bir alt yapı ile tamamlanmış olan "yüksek iç 
tasarruf" oranlarının, ülkeleri kısa dönemli uluslararası sermaye akımlarındaki dalgalanmalardan kaynaklanan krizlerden koruması beklenmektedir (Naim, 1999:5). Ancak Meksika krizinden iki yıl sonra 1997-98 yıllarında Güney Kore, Malezya, Tayland ve Endonezya, 1998 yılında Rusya ve Brezilya, 2001 yılında Türkiye, 2001-2002 yılında Arjantin'de benzer krizler yaşanmış ve "finansal serbestleştirme" sonucu ortaya çıkan sıcak para hareketleri özellikle gelişmekte olan ülkeler için krizlerin tetikleyicisi olmuştur.

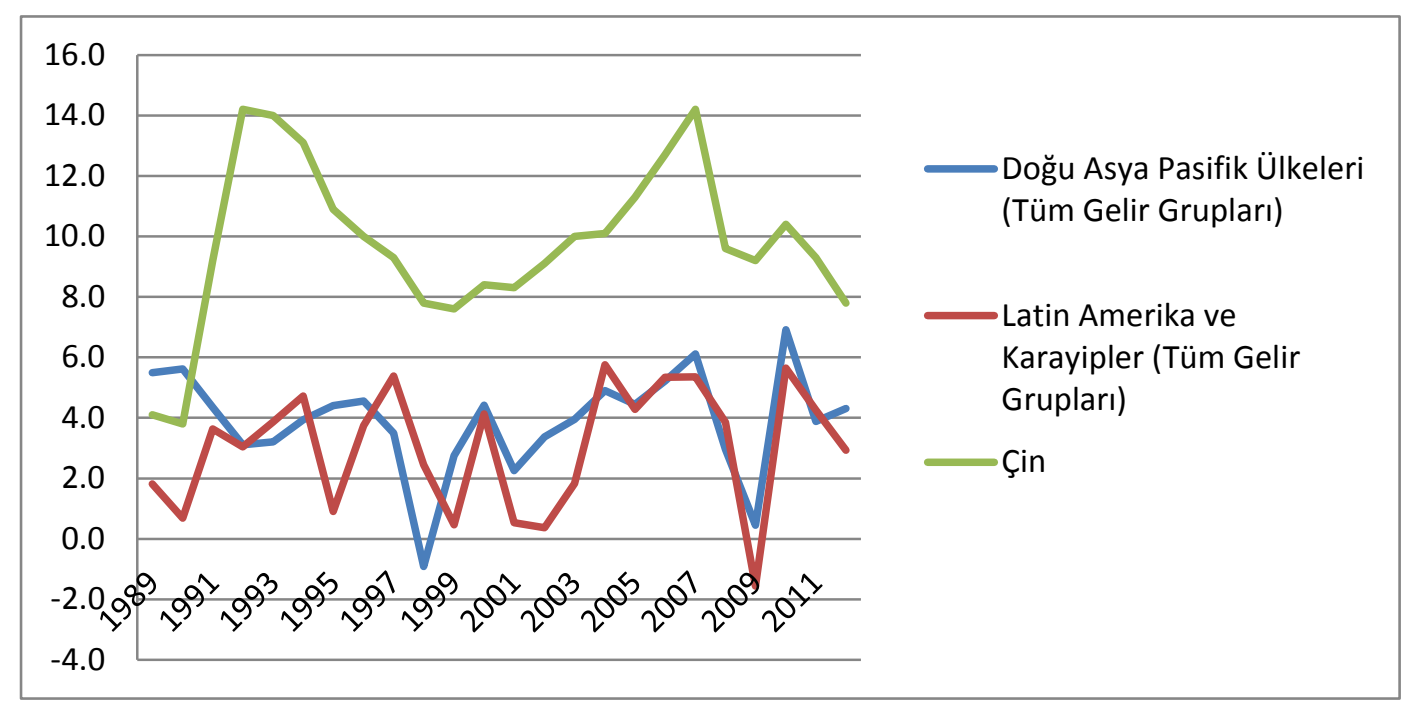

Şekil 2. Gayri Safi Milli Gelire Oranla Dış Borç Stoku Kaynak: Dünya Bankası Veri Dağıtım Sistemi

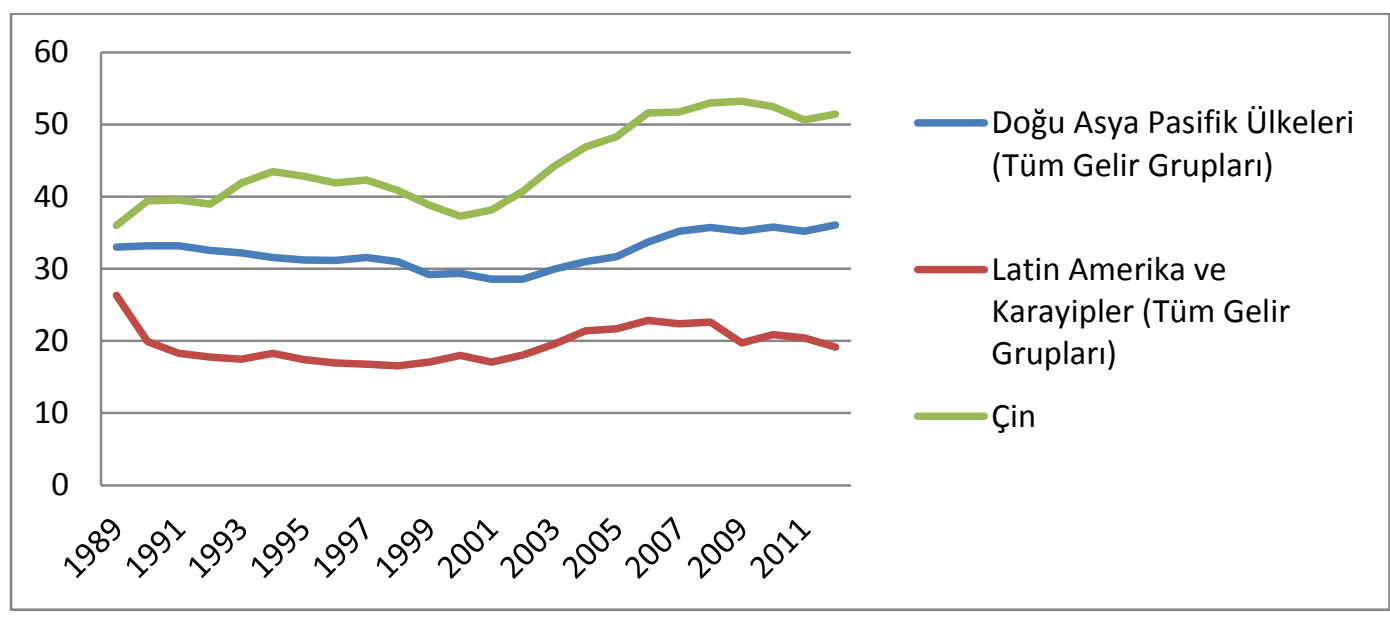

Şekil 3. Ylllık Yüzde Büyüme Oranları (2005 ABD Dolarıyla) Kaynak: Dünya Bankası Veri Dağıttım Sistemi

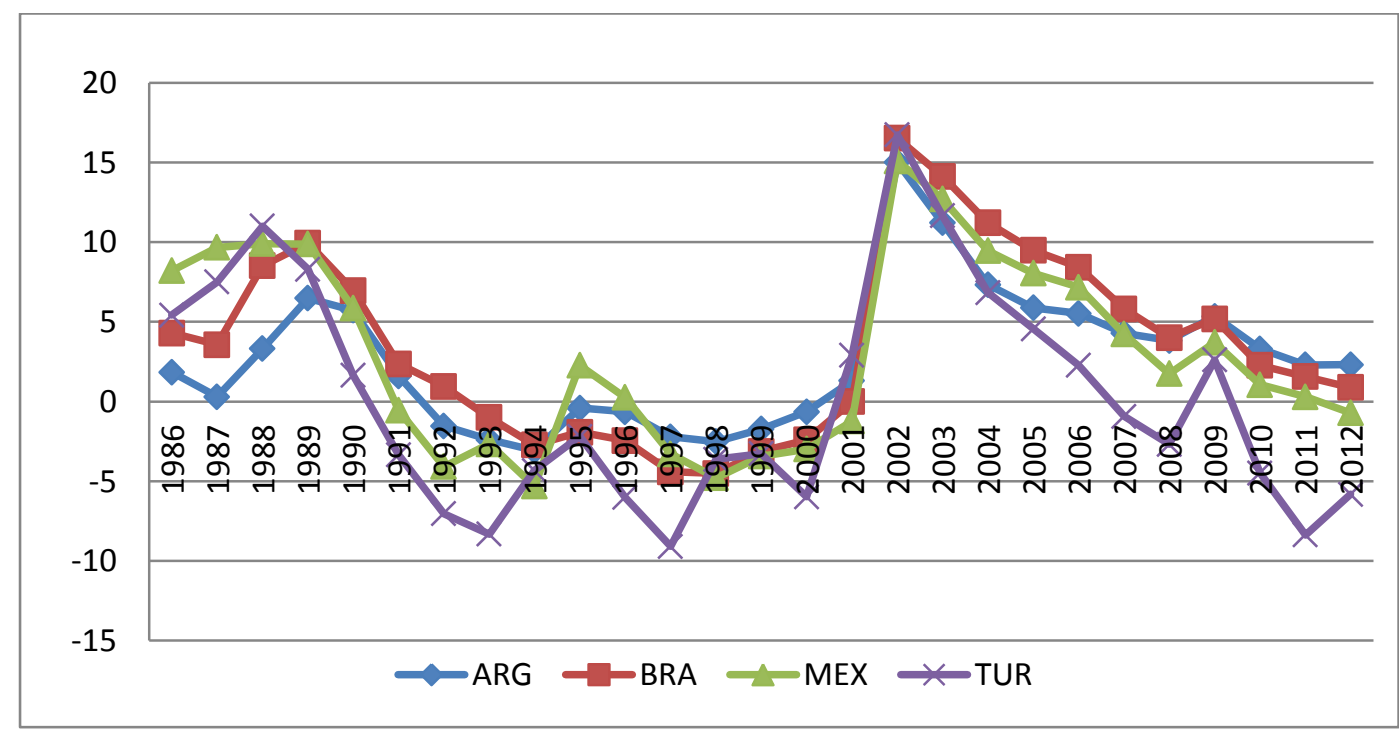

Şekil 4. Mal ve Hizmet Dengesi (GSYiH’nin Yüzdesi) Kaynak: Dünya Bankası Veri Dağıtım Sistemi 
Yukarıdaki 3 nolu şekil 1990’lı yıllarda hem Doğu Asya ülkelerinde hem de Latin Amerika Ülkeleri’nde tasarruf oranlarının azaldığını, bu azalmanın Latin Amerika Ülkeleri için özellikle çarpıcı olduğunu göstermektedir. Washington Uzlaşısının dışında kalan ve bu politikalara ihtiyatla yaklaşan Çin ise hem yüksek tasarruf oranına sahip olmuş hem de tasarruflarını artırabilmiştir. Tasarruflar bir ülkenin yatırım yapma kapasitesini belirleyen önemli bir kaynaktır. Eğer bir ülkenin yatırımları tasarruflarını aşıyorsa yatırımları finance etmenin iki kaynağı bütçe ile dış ticaret açı̆̆ıdır. Dış ticaret açığı ise bir süre sonra kapatılamazsa Cari İşlemler Hesabında (CIHH) bir açığa neden olur ve bu açık yapısal bir hale gelebilir. Sonrasında ise bu açığın kapatılmasının finansmanı sorunu başlayarak, döviz kuru-faiz oranı ve parasal genişlemeler üzerinde bir baskı oluşturur. Aşağıda 4 nolu şekilde seçilmiş üç önemli Latin Amerika ülkesiyle Türkiye'nin dış dünyayla yaptığ 1 mal ve hizmet dengesinin GSYİH'ya oranı yüzde olarak sunulmaktadır. Bu dört önemli ülkenin de 1989 öncesi fazla veren mal ve hizmet dengesi 1989 Washington Uzlaşısı sonrası hızla negatife dönmüş, 2001 sonrası artma eğilimi gösteren bu oran günümüze kadar hızla azalma eğilimine göstermiştir. Bu olgu aynı zamanda ülkelerin cari açık vermelerinde de esas rolü oynamaktadır.

1990’lı yıllarda yaşanan gelişmeler Washington Uzlaşısı için genel olarak olumlu sonuçlar vermemiş, bu politikaları uygulamayan ülkeler açısından durum en azından daha kötü olmamıştır. Rodrik'e göre, Çin, Hindistan, Şili gibi ülkeler büyürken diğer ülkelerde yaşanan krizlerin önemli nedenlerinden biri reformların tek taraflı olarak devletin rolünün azaltılması ve piyasaların etkinliğinin artırılması şeklinde yapılırken, kurumların ihmal edilmiş olmasıdır. Reel kesimi desteklemeyen kurumlar, ülkelerin dışa açılmasında başarısızlık yaratacaktır (Rodrik, 2006). Bu noktada her ülkenin farklı iktisat politikalarına ihtiyaç duyacağı ve bu nedenle Washington Uzlaşısı içindeki bu maddelerin her ülke için uygun olmayabileceği görüşü ağırlık kazanmış ve bu eleştiriler karşısında II. Washington Uzlaşısı olarak adlandırılan ek 10 maddelik bir reform paketi gündeme gelmiştir.

\section{1 İkinci Nesil Washington Uzlaşısı}

Tasarruf oranları, emeklilik reformu, sermaye kaçışı, şeffaflık ve yönetişim gibi konular 1990'lardan itibaren uzmanlar, politikacılar ve piyasa reformlarıyla ilgilenenler arasında sürekli tartışma odağı olmuştur. Bu terimlerin hiçbiri orijinal Washington Uzlaşısında yer almamıştır (Naim, 1999:5).

Bu ikinci nesil reformlar, “yönetim reformları” başlığı altında şekillenmiştir. İkinci Nesil Washington Uzlaşısı ile ortaya konulan en önemli farklılık, neoliberal reformların, piyasa dışı faktörleri de kapsayacak şekilde genişletilmesi ve sosyal normlara ve kurumsal yapılara önem veren bir yaklaşımın ortaya konmasıdır. Rodrik'e göre birinciye ek olarak ikinci Washington Uzlaşısında yer alan maddeler şunlardır (Rodrik, 2006:978):

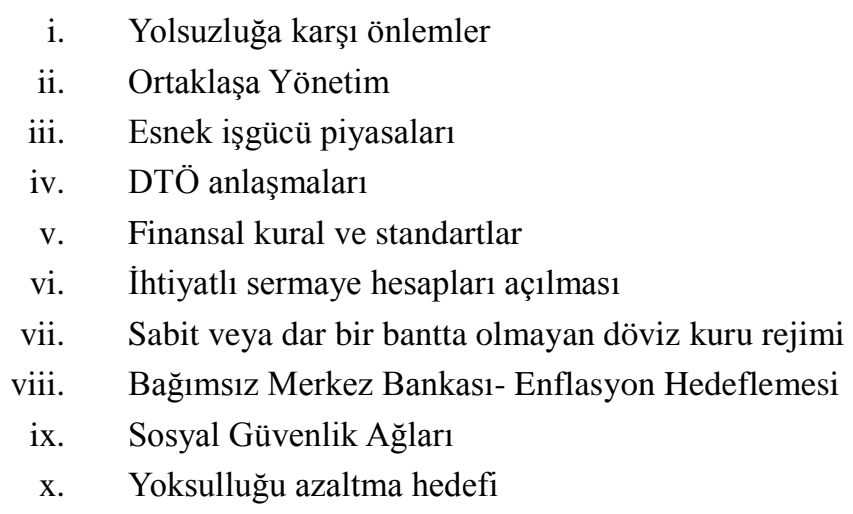

$\mathrm{Bu}$ çerçeveden bakıldığında, İkinci Nesil Washington Uzlaşısı yaklaşımında, devlet ile piyasanın birbirinin tamamlayıcısı olduğu ve özellikle kalkınma sürecinde devletlerin etkinliğinin pazarın doğru işleyişi için, önemli bir rol oynadığı kabul edilmektedir (Öniş ve Şenses, 2005). Bu gelişmeler 1şı̆̆ında, Dünya Bankası 1985 y1lında "yoksulluğa duyarlı büyüme" stratejisini benimserken, 1987 yılında "yapısal uyumun sosyal boyutları" yaklaşımını benimsemiş ve 1989 yılından sonra da "yönetişim" kavramını ortaya koymuştur ( Akçay ve Türkay, 2009: 319). Dolayısıyla minimum devlet anlayışı 1990’larda “devletin yönlendiriciliği” şekline dönüşmüştür.

Rodrik'e göre sanayileşme yoluyla hızlı büyümeyi destekleyen küreselleşmenin gelişmekte olan ülkeleri aynı zamanda ara malı ithalatına bağımlı hale getirebileceği, bu düzende kalkınmanın ise kendiliğinden olmasını beklemenin hayalcilik olacağının altını çizmektedir. Gelişmekte olan ülkelerde en bağlayıcı kısıt finansman azlığıdır. İkinci Washington Uzlaşısında yer alan 5, 6 ve 7. maddeler bu açıdan ani uluslararası finans hareketlerinin sıkıntılarını önlemeye yönelik tedbirlerdir. Bu ülkelerde riski arttıran diğer nedenler enflasyon ve devlet borçlarıdır. Girişimcilerin ilk maliyetlerinin yüksek olması da önemli bir etkendir (Rodrik, 2011:151-153).

Bu durumda öncelikle bu tip ülkelerde ekonomik büyüme üzerindeki engellerin nerede olduğunu anlamak (teşhis) ve bu engelleri aşmaya uygun yaratıcı politikalar tasarlamak gerekmektedir. Ancak, ekonominin dinamik kalmasını sağlamak ve büyümeyi boşa çıkarmamak için teşhis ve politikalar sürecini kurumsallaştırmak gerekmektedir. Rodrik teşhis için aşağıda yer alan tanımlamayı yapmıştır (Rodrik, 2006:983): 
Problem: Gelişmekte olan ülkelerde özel yatırım ve girişimciliğin düşük düzeyde olması

\begin{tabular}{|l|l|}
\hline A)Ekonomik faaliyetler için düşük getiri & B) Finansman maliyetinin yüksek olması \\
\hline i) Düşük sosyal getiri & i) Yetersiz uluslararası finansman \\
\hline Fakir coğrafya; düşük beşeri sermaye; yetersiz altyapı & ii) Yetersiz iç finansman: Düşük iç tasarruflar \\
\hline ii) Düşük ödenek & \\
\hline Hükümet hataları (Mikro riskler: mülkiyet hakları, & \\
rüşvet, vergiler & \\
Makro riskler: finansal; mali istikrarsızlık) & \\
Pazar hataları (Bilgilenmede dışsallıklar: kendi başına & \\
keşfetme; koordinasyon dışsallıları) & \\
\hline
\end{tabular}

Tablo 1:Büyümenin Önünde Engel Teşkil Edecek Olguların Teşhisi Kaynak: Rodrik, D. (2006)

Tablo 1'de teşhis analizini incelediğimizde, çok temel ancak güçlü bir sınıflandırma görebiliriz. Düşük gelirli bir ekonomide, ekonomik faaliyetler en azından ya finansman maliyetlerinin çok yüksek olmasından ya da özel yatırımların getirilerinin çok düşük olması nedeniyle kısıtlanabilecektir. Şayet problem özel yatırımların düşük getirisi ise, bu da dönüp düşük getiriye veya kamu ve özel getiriler arasındaki farkın büyümesine neden olacaktır.

Teşhis analizinde ilk adım bu koşullardan hangisinin ekonomideki sorunları tam olarak karakterize ettiğini ortaya koymaktır. Ancak bunlar birbirinden kesin ayrılabilecek nedenler değildir. Örneğin Rodrik'e (2006) göre bir ekonomi finans maliyetleri nedeni ile belli bir baskı altında ise, reel faiz oranlarının yüksek olmasını bekleriz. $\mathrm{Bu}$ durumda borç almak isteyenler borç verenlerin peşinde olacak ve cari açık, dış borçlanmanın mümkün olduğu oranda artacaktır. Girişimciler için yatırımlar cazip olacaktır. Böyle bir ekonomide -dış yardım ve döviz gelirleri gibi- yatırıma dönüşebilir fonlardaki dışsal bir artış, daha çok tüketim veya gayrimenkul yatırımları yerine öncelikle diğer üretken faaliyetleri teşvik edecektir. Tersine ekonomik faaliyetlerin- özel getirilerin düşük olması nedeniyle- azaldığı bir ekonomide, faiz oranları düşük olacaktır. Bankalar likidite bolluğu içinde olacak yani borç vermek isteyenler, borç almak isteyenlerin peşinde olacak, cari işlemler dengeye yakın ya da fazla verecektir. Girişimciler bu durumda paralarını daha yüksek getirisi olan yerlerde değerlendireceklerdir. Yabancı yatırımlar veya döviz gelirlerinin artması El Salvador, Etiyopya gibi ülkelerde gözlendiği gibi tüketimi veya sermaye çıkışını finanse edecektir.

Williamson 1997 yılında, 1989 yılındaki çalışması üzerine bazı eklemeler yaparak yeniden ele aldığı "Washington Uzlaşısını Yeniden Gözden Geçirme" başlıklı yazısında farklı bir yol izlemiştir. Çalışmada Latin Amerika’nın uygulaması gerektiğine inandığı reformlar yine aynı olmakla beraber bazı düzenlemeler görüyoruz. Bunlar: yüksek tasarruf oranları, kamu harcamalarında öncelikler, vergi reformu, bankacılık denetleme, rekabetçi döviz kuru, ticarette serbestlik, doğrudan yabancı sermaye yatırımları, rekabetçi bir ekonomi, mülkiyet hakları, kurumsal yapılanma, eğitimin arttırılması başlıkları altında toplanabilir (Williamson, 1997).

Orijinal Washington Uzlaşısında ilk madde "mali disiplin” iken, tek başına mali disiplinin büyümeyi uyarıcı etkisinin yetersiz olduğu kabul edilmiştir. Yatırımları ve bu yolla büyümeyi arttırmak için önemli bir araç olarak tasarrufları daha fazla teşvik etmeye ihtiyaç vardır. Buradaki en önemli noktalardan bir tanesi tasarruflardaki artışın kamu sektöründen çok özel sektörden kaynaklanmasıdır. Bu noktada yüksek vergiler bu teşviği azaltacaktır. Etkili bir mali disiplinin, özel kesim tasarruflarında bir artış ile desteklenmesi ve bunu özendirmesi gerekmektedir (Marangos; 2008: 362).

Diğer taraftan dünya ticareti tek taraflı tarife indirimlerinden serbest ticaret bölgeleri ve ikili anlaşmalara dönüşmüştür. $\mathrm{Bu}$ gelişmeler dünya ticaretinin liberalleşmesi süreci ile uyumludur. $\mathrm{Bu}$ durum Washington uzlaşısının ilk halinden biraz farklıdır. İlk halinde daha çok altı çizilen dışa dönük bir ticaret politikası izlenebilmesi ve yolsuzlukların azaltılabilmesi için ithalat liberalizasyonu ve dış ticaret üzerindeki nicel sınırlamaların kaldırılması gerekliliğidir. Bebek endüstriler ile ilgili kaygılar bu sektörlerdeki geçici korumayı desteklemektedir. Uygulanacak genel bir ortalama tarife (\%10-20 civarında) önemli bir maliyet yaratmadan endüstriyel bazda bir çeşitlendirme yaratacaktır. Üzerinde tam uzlaşılamayan konu korumanın yaklaşık üç ile on yıl arasında kaldırılması ile (Dünya Bankasının görüşü), Williamson'ın savunduğu bu sürenin ülkenin makroekonomik koşullarına bağlı olduğu görüşüdür (Marangos; 2008: 359-362).

Doğrudan yabancı sermayenin girişi ile ilgili olarak, yabancı firmaların girişini engelleyen kısıtların kaldırması yerli ve yabancı firmalar arasındaki rekabeti artıracaktır. Yabancı yatırımlar, ihtiyaç duyulan sermayeyi, teknolojiyi ve beceriyi getirirken, iç piyasa için gerekli üretimi yapabilecek ve ihracata katkıda bulunabilecektir. Washington Uzlaşısında ekonomik anlamda bir milliyetçiliğe yer yoktur. Bu reform Latin Amerika ülkelerinde başarılı olduğu için üzerinde tekrar tartışılmamıştır. Aşağıdaki 5 nolu şekil dört Latin Amerika ülkesi için net doğrudan yatırımların GSYİH'ya oranını göstermektedir. Bu çerçevede 1989-2012 dönemi bu ülkelere net sermaye yatırımlarının pozitif olduğunu göstermektedir. Bu ülkeler içerisinde en avantajlı ülkenin Şili olduğu gözükmektedir. 


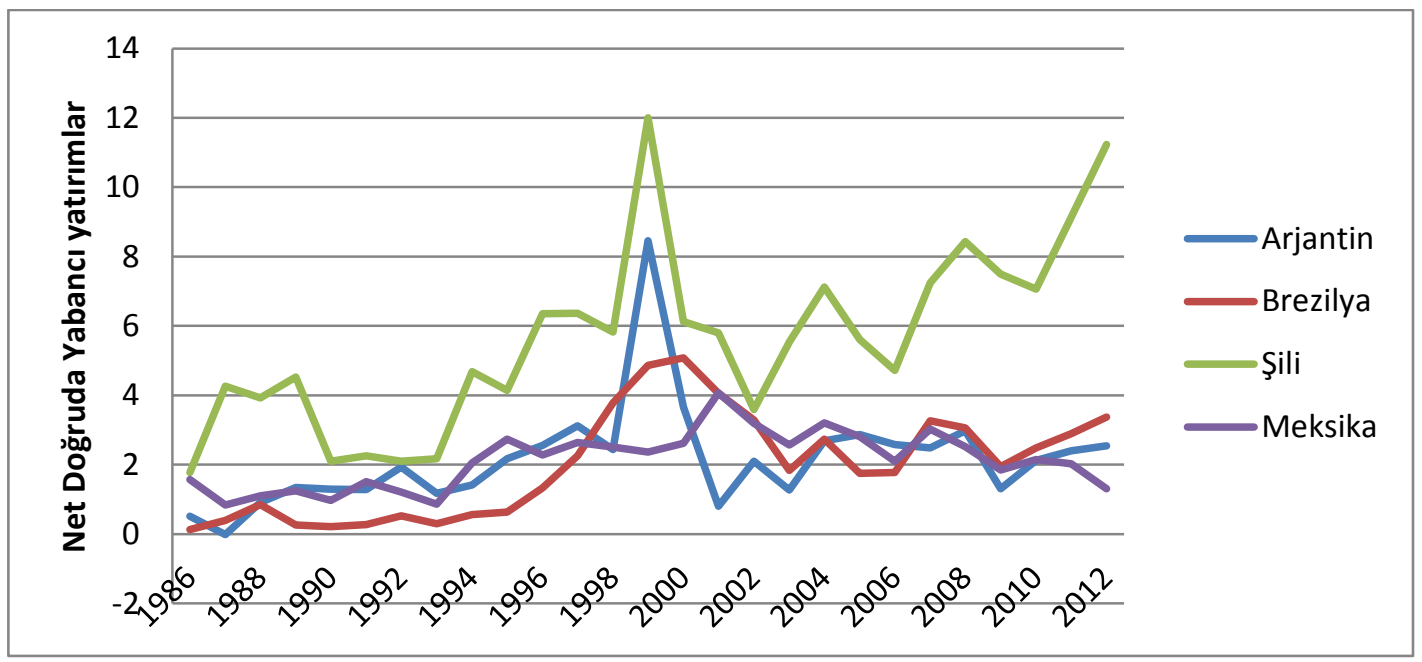

Şekil 5. Net Doğrudan Yabancı Yatırımların GSYİH’ya oranı Kaynak: Dünya Bankası Veri Dă̆ıtım Sistemi

Diğer taraftan eğitim konusunda, ilk konsensusta kamu harcamalarının öncelikli olarak eğitime yönlendirilmesi tavsiye edilmiştir. Daha sonrakinde ise, eğitim kendine özgü bir konu olarak ele alınmıştır. Zira eğitimli bir işgücü, ekonominin hızlı gelişmesinde önemli bir önkoşuldur. İyileştirilmiş bir eğitim ekonomik büyüme, gelir dağılımı ve çevre için özel bir önem taşımaktadır.

\section{Washington Uzlaşısında Yer Alan Konulara Post-Keynezyen Alternatif Yaklaşım}

Washington Uzlaşısına yönelik özel bir politika seti geliştirilmemiş olmasına rağmen dünya ekonomik sisteminin genel işleyişi içerisinde kalmak kaydıyla Post-Keynezyenlerin sistematik alternatif politika önerilerini bulmak mümkündür. Post-Keynezyenlerin kendi aralarındaki teorik uyumu pratik dünyanın gelişmeleri de göz önüne alınarak tartışmalı bir şekilde ilerlemektedir. Ancak Washington Uzlaşısında dile getirilen öneriler konusunda net teorik itirazlarının olduğu da açıktır (Marangos, 2012; Davidson, 2004-2005). Bu itirazların kökeninde Post-Keynezyenlerin iktisada yöntemsel yaklaşımları içerisinde yer alan eleştirel gerçekçilik (critical realism) ve gerçek dünyayı dikkate alan açıklamalara verdikleri özel önemin ayrı bir yeri vardır. Bu nedenle Washington Uzlaşısı içerisinde yer alan politika önermelerine Post-Keynezyenlerin uygulamaya da bağlı olarak teorik karşı çıkışlarının kısa incelemesinin yapılması hedeflenmiştir.

\subsection{Mali Disiplin}

Washington ve Post Washington Uzlaşısındaki mali disipline yönelik önermeleri Post-Keynezyenler kesin bir şekilde kabul etmemektedir. Mali disiplinden kastedilen bütçe açıklarının enflasyon ve ödemeler dengesi açıkları gibi makroekonomik dengesizliklere yol açmasıdır. Bu nedenle bütçe açıklarının kapatılması ve/veya küçültülmesi önerilmektedir. Post-Keynezyenler maliye politikasına önem verdiklerinden bu anlamda bir bütçe disiplinini desteklememektedirler. Kamu harcamaları tam istihdama giden yolda kaçınılmaz bir biçimde gereklidir. Özel kesim yatırımlarının kamu harcamalarıyla dışlanması zorunlu bir sonuç değildir. Tam tersine kamu harcamaları özel kesim yatırımlarını tamamlayıcı bir işlev görebilirler. Bütçe açıklarının faiz oranlarını yükseltmesiyle ilgili ampirik bulgular zayıftır. Merkez bankası para stokunu kredi parası olarak ayarlayabileceğinden faizler (para arzı içselliği) üzerine kamu harcamalarının ilave bir baskı yapması kaçınılmaz değildir. (Nevile, 2003). Kamu açıkları durgunluğu önlemek için verilebilir. Fakat Durgunluğun nedeni değildir (Marangos, 2012).

\subsection{Kamu Harcamalarının Önceliği}

Kamu harcamaları eğitim, sağlık ve alt yapı harcamaları gibi toplumun refahını artıran alanlara öncelikli olarak yapılmalıdır. Harcamalar aynı zamanda verimliliği artırarak özel kesim yatırımlarına ve büyümeye olumlu bir etki yapar. İşsizlerin yeniden eğitimi için oluşturulacak kamu fonları nitelikli işgücünün oluşmasına ve dolayısıyla verimliliğin artmasına yol açar. Toplumsal eğitim alanına yapılacak yatırımlar toplumsal maliyetleri (suçluların azalması gibi) azaltıcı bir etki yapar. Gelir dağılımını düzeltici harcamalar toplam talebin de istikrarlı olmasina neden olur.

\subsection{Vergi Reformu}

Post-Keynezyenler açısından vergi sistemi sadece gelir elde etme yönüyle değil, toplumun kültürel ve sosyal alt yapısını yansıtması bakımından da önem arz eder. Toplumsal yönüyle vergi kaçağının önüne geçmek, bütçe açığının azaltılması için harcamaları düşürmek kadar önemlidir (Marangos, 2012). Post-Keynezyenlerde vergilendirme konusu Polonyalı iktisatçı Kalecki tarafından formüle edilmiştir (Laramie va Mair, 2003): 
Kalecki kısa dönem modelinde Milli Gelirin elde edilmesi ve yeniden dağılımı, malların, sermayenin ve gelir gibi değişkenlerin vergilendirilmesinin etkileri üzerinde durmuştur. Kısa dönemde ücret ve karın vergilendirilmesinin karlar üzerine etkisinin uzun dönemde yatırımlar üzerinde etkili olabileceğini göstermiştir. Ücret ve karların vergilendirilmesi iş çevrimlerinin genişliğini ve yatııım oranlarının trendini etkileyebilecektir. Vergi sisteminin etkilediği amortisman ve kar düzeyi gibi iki kanal bulunmaktadır. Vergilendirme teknolojik gelişmeler sonucunda fiziksel ve finansal olarak eskimiş sermaye mallarının daha üretken, daha karlı sermaye mallarıyla değişimini hızlandıracaktır. Karların vergilendirilmesi karların seviyesi üzerinde doğrudan bir etkide bulunurken, milli gelir içinde ücretin payı üzerinde dolaylı bir etkide bulunarak toplam karlılığı belirleyen harcamaları etkileyebilecektir. Bu durum maliye politikasının bir istikrar unsuru olarak kullanılabileceğine işaret etmektedir. Yerel yönetimlerde politik nedenlerden dolayı farklı bir vergilendirme sistemi tercih edilebilir. Ancak kamu gelir ve harcamaları bir bütün olarak bu farklı tercihlerin makro ekonomik etkisinden bağımsız kalamaz.

Kaleckici bu analiz Washington/Post-Washington önermelerinin arz yanlısı iktisat anlayışına dikkate değer bir alternatif bakış açısını temsil etmektedir. Arz yanlısı iktisat gelir dağılımını marjinal verimliliğe bağlarken ekonominin arz yönlü olarak belirli sınırlandırmalar altında olduğunu ifade etmektedir. Ortodoks arz yanlı iktisada göre ücretler emek piyasasında belirlenirken, Post-Keynezyenler reel ücretin mal piyasasında belirlendiğini ileri sürmektedirler. Vergileri değiştirmenin (ücretler ve karlardan alınan vergiler) makroekonomik etkisi iş dünyasının mark -up oranlarına vereceği tepkiye bağlı olarak belirlenir. Bu tepkide monopol derecesine bağlı olarak ücretin ve karın milli gelir içerisindeki payını belirler.

\subsection{Finansal Serbestleşme}

Post-Keynezyenlerin Washington/Post-Washington finansal serbestleşme önermelerine hem teorik hem de uygulama deneyimleri açısından eleştirileri bulunmaktadır. Uzlaşılarda belirtilen finansal serbestleşmeden kastedilen, kredilerin dağılımının ve faizlerin piyasa tarafından belirlenmesidir. Böylece tasarruflar ve sermayenin etkinliğinde pozitif etkilenmeler olacaktır. Bu durum 1950-1970'li yılları kapsayan dönemde özellikle gelişmekte olan ülke merkez bankalarının belirlediği ve göreli düşük tuttuğu faiz oranlarına bir tepki niteliğindedir. Yüksek reel pozitif faizler tasarrufları ve yatırımları artırırken düşük getirili sermayenin de tavsiyesine yol açacaktır. Sermayenin ortalama verimliliği artarken büyüme yükselecektir. Dolayısıyla merkez bankaları kamu otoritesinden bağımsız olmalı, sermaye akımları serbest bırakılmalı, faizler ve krediler piyasa koşullarına bırakılmalıdır. Bir dizi finansal reformlar yapılmalı, enflasyon düşük ve istikrarlı olmalıdır. Oysa bu görüşlerin teorik dayanağı oldukça tartışmalıdır.

Finansal piyasaların serbestleşmesi konusunda üç çekince önemlidir (Arestis, 2004): İlki asimetrik bilgidir. Asimetrik bilgi, ters seçim ve ahlaki bozulmalar ortaya çıkarır. Örneğin yatırımcı yatırımlarının riskini tam bilemez. Kredi kullanmıştır. Kredi kullandıranda yatırımcının riskli bir yatırım yaptığını bilememesi durumunda ahlaki bir bozulma ortaya çıkar. İkincisi belirsizliktir. Bütün kredi piyasası belirsizlik altında çalışır. Tamamen serbest bırakılan bir piyasa belirsizliğin olumsuzluklarını artıracaktır. Bunun için deregülasyon değil daha iyi bir regülasyon önerilebilir. Üçüncüsü, serbestleşme, finansal baskıları, finansal kırılganlıkları ve krizleri artırabilir.

\subsection{Döviz Kuru}

Ortodoks yaklaşım döviz kurlarının mal ticaretine dayalı olarak değiştiğini ve uzun dönemde mal ticaretine bağlı olarak belirlenen kurların ticareti dengeye getirecek uyarlamayı sağladığına yönelik bir yaklaşıma odaklanmış durumdadır. Döviz kuruna Post-Keynezyen yaklaşım sermaye akımlarının ekonomide aktif ve otonom olduğuna iliş̧in bir yargı çerçevesinde oluşmaktadır. Post-Keynezyenler ampirik bulgulara da dayanarak ticaretin denge eğilimi göstermediğini ve ulusal paranın değerinin uluslar arası portföy yatırımcılarının kararlarına bağlı olarak belirlendiğini savunmaktadırlar. Paranın değer kaybı/kazancı bu yatırımcıların ulusal varlıklara yönelik talebinin bir sonucu olarak belirlenir. Bu yatırımlarda belirsizlik koşulları altında ticaret dengesinin sağlanmasına değil fakat döviz kurunun oynaklı̆ğıa yol açarak dengesizliğin sürmesine neden olur. Keynes, Bretton Woods konferansında sermaye hareketliliği üzerinde bir denetimde bulunmalarının ulusların hakkı olduğunu ileri sürmüş, ancak tamamen reddedilmese de genel bir kabul görmemiştir. Fakat son zamanlarda Post-Keynezyenlerin de etkisiyle sermaye kontrolleri yeniden önem kazanmıştır (Harvey, 2003). Döviz kuru rejimi olarak Post-Keynezyenler, ayarlanabilir dalgalı döviz kuru rejiminin gelişmekte olan ülkeler ile sanayileşmiş ülkeler için önerilebileceğini, ancak bu rejimin uygulanabilmesi için sermaye kontrollerinin yapılmasının gerekli olduğunu belirtmektedir (Chang ve Grabel, 2004).

\subsection{Ticaretin Serbestleșmesi}

Post-Keynezyenler bir ülkenin büyüme hızını artırmak için mutlaka dışa açılmalarının gerekmediğini savunurlar. Ülkeler başlangıçta yeni gelişen sanayilerini korumalı ve seçici bir ihracat teşviki uygulamalıdırlar. Hızlı büyüme ve verimlilik artışı ülkelerin dışa açılmasını daha mümkün kılar. Verimlilik artışıla dışa açılan bir ülkenin yeni gelişen sanayilerini koruma ihtiyacı azalır. Yoksul ülkeler için ödemeler dengesi açıkları büyümenin önünde bir engel oluşturur. Diş açıklar döviz kurunda krizler, enflasyon ve işsizlik yaratarak yoksulluğun artmasina neden olur. Ülkeler ulusal bankacılık sistemi ve iç makroekonomik politikalardan asla vazgeçmemelidir (Marangos, 2012). 


\subsection{Doğrudan Yabancı Yatırımlar}

Yabancı sermaye girişlerinin iç yatırımları artırdığına yönelik yeterli bir kanıt bulunmamaktadır (Kregel, 2008). Bunun yerine dış yatırımların istikrarlı olmasına, ülke yatırımlarının toplamı içinde makul bir düzeyde bulunmasına ve kısa dönemli kar getirilerinden ziyade ülkenin kalkınmasına hizmet edecek alanlarda yatırım yapmasına önem verilmelidir. Çin, Kore, Tayvan gibi ülkeler, yabancı yatırımcılara sıkı bir düzenlemeye rağmen başarılı olmuş ülkelere örnek teşkil etmektedir (Marangos, 2012 ve Chang ve Grabel, 2004).

\section{8 Özelleştirme}

Post-Keynezyenlere göre devlet mülkiyetinin bütçe açı̆̆ı ve kaynakları etkinsiz kullandıkları yönünde evrensel bir kural bulunmamaktadır. Ekonomik kalkınma mutlak olarak devlet mülkiyetinden vazgeçilmesini gerekli kılmamaktadır. Ekonomik büyüme için kamu mülkiyeti önemli bir rol üstlenebilir. Bu elbette ekonominin tamamının devlet kontrolü altında olmasını gerektirmez (Saad-Filho, 2007).

\subsection{Yeniden Düzenleme}

Ücretlerin düşürülmesinin ve esnek işgücü piyasasının verimlilik ve yatırımların karlılığı üzerinde olumlu etkileri yoktur. Bunun yerine yasal olarak iyi düzenlenmiş bir piyasa, tatmin edici asgari ücretler ve güçlü sendikaların yatırımları artırıcı ve yeni teknoloji kullanımını teşvik edici sonuçları olabilir. (Saad-Filho, 2007).

\subsection{Mülkiyet Hakları}

Post-Keynezyen bakış açısı piyasa ekonomisinde mülkiyet haklarına önem vermektedir. Bu nedenle toprak reformu gibi politikaları desteklemektedir. Bu durum Post Washington önerilerine aykırı değildir. Buna rağmen Latin Amerika ülkelerinde devlet öncülüğündeki bir sanayileşmenin daha üstün olduğu görülmektedir (Ocampo, 2004).

\subsection{Kurumların İnşası}

Ekonomik ve sosyal kurumların tarihsel, sosyolojik ve ülkenin içinde bulunduğu siyasal demokratik yapısıyla yakın ilişkisi vardır. Günümüzde piyasa ekonomisini uygulayan gelişmiş ülkelerin kendi içinde de heterojen bir yap1 söz konusu olabilmektedir (Chang ve Grabel, 2004; Ocampo, 2004). Anglo-Amerikan Kapitalizm modelinin kendine has kurumları ve düzenlemeleri olabilir. Ancak bu durum piyasa ekonomisini uygulayan her ülke için mutlak bir zorunluluk oluşturmaz. Her ülke kendine özgü kurumları, koşulları topluma eşit yakınlıkta ve demokratik/özgür bir biçimde oluşturmalı ve geliştirmelidir.

\section{Sonuç}

1990’lı yıllar adına Washington Uzlaşısı denilen ve özünde neoliberal politikalar barındıran bir politika demetinin dünya genelinde uygulamaya sokulduğu yıllar olmuştur. Bu politikalardan dağılan iki kutuplu dünya sisteminin sosyalist ülkeler gurubunda yer alan ülkeler de etkilenmiştir. Özünde ülkelerin dış borçlarında azalma, daha yüksek ve istikrarlı bir büyüme, düşük enflasyon ve işsizlik ile mali disiplin öneren bu politikalar genel hatlarıyla başarısız olmuştur. $\mathrm{Bu}$ önerilere uymayan ülkeler ise uzlaşıda önerilen hedeflere daha yakın bir konumda bulunmaktadırlar. Metin içinde sunulan 1-2 ve 3 nolu grafikler bu bulguyu destekler niteliktedir. Nitekim başarısızlık bu politikaları öneren kurumların da dikkatini çekmiş ve Post Washington Uzlaşısı olarak adlandırılan 2. Nesil politika önerileri uygulamaya sokulmuştur. Ancak Rodrik'in de belirttiği gibi Uzlaşının ortadan kalktığı ve yerine neyin alacağının tartışıldığı bir döneme girmiş bulunmaktayız (Rodrik, 2006).

$\mathrm{Bu}$ politikalar çoğunlukla tek reçete olarak sunulmuş ve alternatifin olmadığı savıyla uygulamaya konulmuştur. Oysa mevcut ekonomik sistem içerisinde Post-Keynezyenlerin, Washington/Post-Washington Uzlaşısına sistematik bir karşı çıkışları söz konusudur. Bu itiraz bütüncül bir alternatifi de bize sunmaktadır: istihdamı optimum seviyesine ulaştırmak için kamu yatırımlarının kullanılması, sanayi politikası uygulamaları, modern bir devlet yaratmak için sosyal politikalar, vergi tabanını genişletmek için modern bir vergi sistemi, gelirin yeniden dağıtılması, sermaye kontrolleri, demokratik mekanizmalarla seçilmiş yönetime ve politikalarına bağımlı bir merkez bankası, kamu mülkiyetinin devam etmesi, ayarlanabilir dalgalı bir döviz kuru sistemi ile sosyal uyumu ve çatışmaları yönetecek içsel kurumların oluşturulmasıdır. Bu önermelerin teorik alt yapısı modern iktisadın doğuşundan itibaren yapılan ve iktisat literatüründe geniş bir yer bulan tartışmalarda mevcuttur. Biz bu kısa çalışmamızda makroekonomik politikaların tüm ülkelerin geneline aynı içerikte ve tek reçete olarak sunulmasının ve politika uygulamalarının ülke ekonomilerine olumlu sonuçlar vermeyebileceğini göstermeye çalışmış durumdayız. Uygulanan politikaların başarısızlı̆̆ alternatif önerilere olan ihtiyacı güçlendirmektedir. Şimdilik bu ihtiyaca Post-Keynezyenler ciddi alternatifler sunmuş gözükmektedir.

\section{Kaynakça}

- $\quad$ Akçay, Ü. Ve Türkay, M (2009), "Neoliberalizmden Kalkınmacı Yaklaşıma: Devletin Sermaye Birikimi Sürecindeki Yeri Üzerine”, Sermaye Birikimi, Kalkınma, Azgelişmişlik, SAV Yayınları, İstanbul.

- Chang, H.J. ve Grabel, I. Reclaiming Development: An Alternative Economic Policy Manual. London: Zed Books, 2004 
- Davidson, P. (2004), "A Post Keynesian view of the Washington consensus and how to improve it" Journal of Post Keynesian Economics, Vol. 27, No. 2, pp. 207-230

- Dünya Bankası Veri Dağıtım Sistemi, http://data.worldbank.org/

- Harvey, J. T. (2003), "Exchange Rates”, The Elgar Companion to Post Keynesian Economics içinde, Edt. J.E. King,, Edward Elgar Cheltendam, UK.Northampton, MA, USA, 2003

- Kregel, J. (2008). "The discrete charm of the Washington concensus" Journal of Post Keynesian Economics, Vol.30, No.4, 541-560

- Laramie ve Mair (2003), “Taxation”, The Elgar Companion to Post Keynesian Economics içinde, Edt. J.E. King,, Edward Elgar Cheltendam, UK.Northampton, MA, USA, 2003

- Marangos, J. (2012), “The Post Keynesian retort to “After the Washington Consensus”, Journal of Post Keynesian Economics, Vol.34, No.4, 583-609

- Marangos, J. (2008), "The Evolution of the Anti-Washington Consensus Debate: From 'Post-Washington Consensus' to 'After the Washington Consensus', Competition \& Change, Vol. 12, No. 3, September 2008 227-244

- Marangos, J. (2009), "The Evolotion of the Term 'Washington Consensus", Journal of Economic Surveys Vol. 23, No. 2, pp. 350-384

- Naim, M. (1999), "Fads and Fashion in Economic Reforms: Washington Consensus or Washington Confusion?" Foreign Policy Magazine,

- Nevile, J.W. (2003), "Fiscal Policy”, The Elgar Companion to Post Keynesian Economics içinde, Edt. J.E. King,, Edward Elgar Cheltendam, UK.Northampton, MA, USA, 2003

- Ocampo, J.A. (2004), “Corporate social responsibility” Natural Resources Forum, Editorial, 28, 249-250

- Öniş Z. ve F.Şenses (2005), "Rethinking the Emerging Post-Washington Consensus", Development and Change 36(2), pp. 263-290

- Rodrik D. (2006), “Goodbye Washington Consensus, Hello Washington Confusion? A Review of the World Bank's Economic Growth in the 1990s: Learning from a Decade of Reform”, Journal of Economic Literature

- Rodrik, D. (2011), “The Globalization Paradox: Democracy and the Future of the World Economy” World Trade Review, 10:3, 409-421

- $\quad$ Saad-Filho, A. (2007), "Life Beyond the Washington Consensus: An Introduction to Pro-Poor Macroeconomics Policies” Review of Political Economy, 19 (4), 513-537 Vol. XLIV, pp. 973-987

- Williamson, J. (1997), The Washington Consensus revisited. In L. Emmerij (ed.), Economic and Social Development in the XXI Century (pp.48-61). Washington, DC: Inter-American Development Bank

- Williamson, J. (2004-2005), "The Strange History of the Washington Consensus", Journal of Post Keynesian Economics, Vol. 27, No. 2, pp. 195-206 